\title{
Enteral Nutrition Support for a Sarcopenia in End-Stage Liver Disease
}

Jefferson

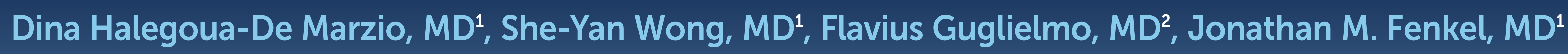

${ }^{1}$ Department of Medicine, Division of Gastroenterology and Hepatology and ${ }^{2}$ Department of Radiology,

Thomas Jefferson University, Philadelphia, Pennsylvania, USA

\section{INTRODUCTION}

Weight loss with muscle wasting, also known as sarcopenia, commonly occurs in patients with end-stage liver disease (ESLD).

A robust association between sarcopenia and mortality in cirrhotic and post-liver transplant patients has been reported. This is a report of a patient with severe sarcopenia and teSLD (DHT) pro priver transtent resulting in successul bridging to transplant.

\section{CASE REPORT}

A 59 year old male with chronic hepatitis C-related cirrhosis was awaiting liverkidney transplant. Complications of his ESLD hepatic encephalopathy, varicel bleeding and refractory accites.

hepatic encephalopathy, variceal bleeding and refractory ascitos

In addition, the patient continued to lose weight. The patient reported poor appetite and decreased oral intake. His body mass index (BMI) had fallen to $17.2 \mathrm{~kg} / \mathrm{m}^{2}$ and
raised concern by our transplant team about his ability to raised concern by our tran
survive transplantation.

survive transplantation.
Past surgical and family histories were unremarkable.

Physical examination was notable for cachexia, temporal and thenar wasting, moderate abdominal distension and lower extremity edema.

Significant laboratory data included a pre-albumin of $6.0 \mathrm{mg} / \mathrm{dL}$ and albumin of $2.1 \mathrm{~g} / \mathrm{dL}$.

Pre-transplant computed tomography of the abdomen and pelvis (CT a/p) of this patient revealed a mean total psoas area (TPA) of $820.70 \mathrm{~mm}^{2}$ (Figure 1 A-B) indica

A DHT was placed to improve his nutritional status and nasal bridle system to prevent tube dislodgement (Figur Wasal bridlesystem to prevent tube dislodgement (egure 2). With enteral feeding, in addition to oral intake, the patient reported feeling less fatigued and lethargic. He gained $3 \mathrm{lbs}$, his albumin rose to $3.0 \mathrm{~g} / \mathrm{dL}$, and he was not hospitalized simultaneous liver/kidney transplant.
Figure 1: CT Abdomen/Pelvis at L4 Demonstrating Patient Total Psoas Area (TPA)
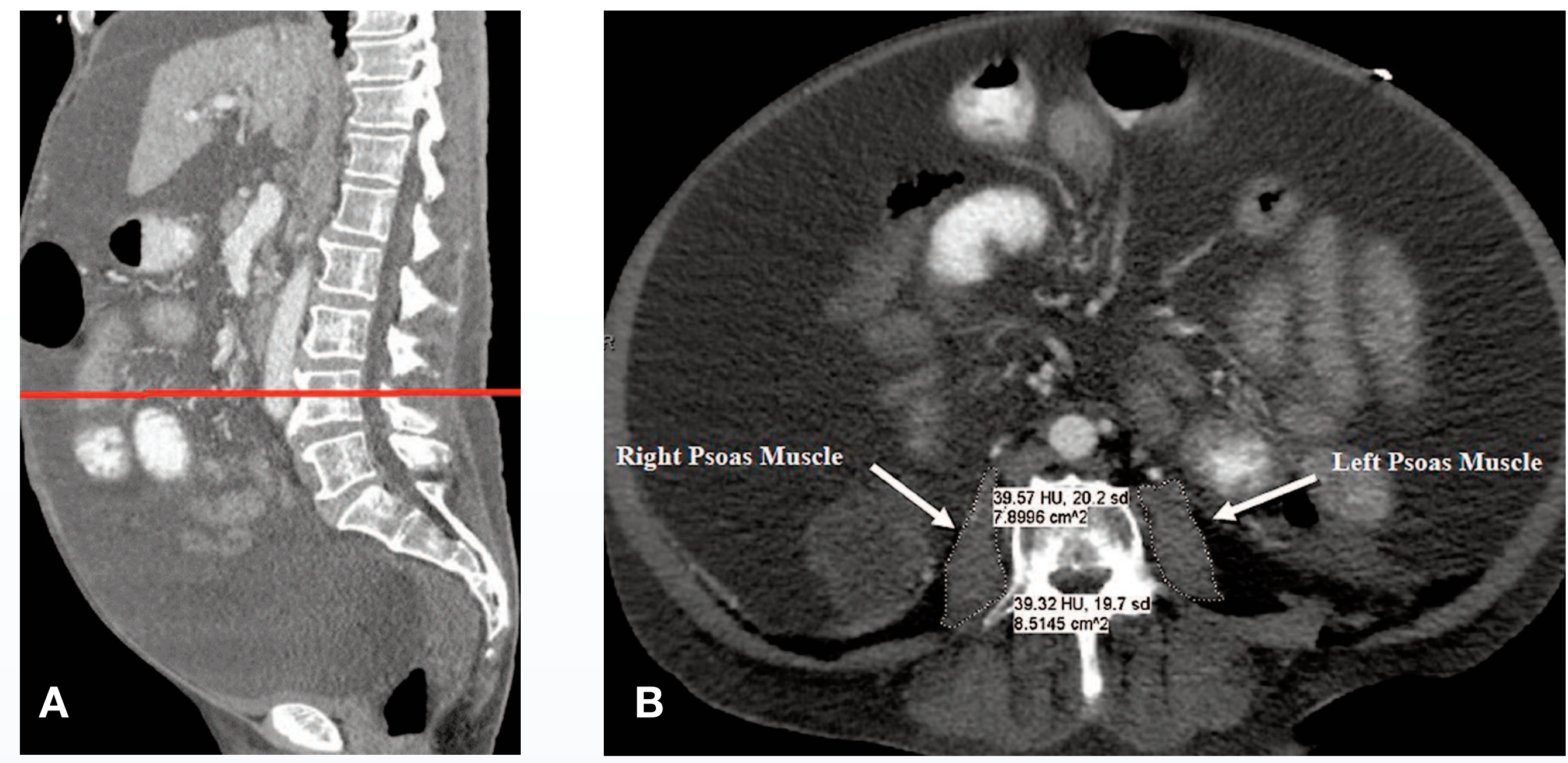

Mean cross-sectional area of the left and right psoas muscle at the level of the fourth lumbar vertebra (L4) was determined. This was accomplidhed by firt denting the individual vertebral levels on a CT scan of the abdomen and pelvis. We then muscle The cross-sectional area (in $\mathrm{mm} / \mathrm{s}$ ) of the enclosed regions was used to calculate the mean total psoas muscle area (TPA). The mean TPA for this patient is 820.70 which is calculated as follows: [(789.96 mm/s $+851.45 \mathrm{~mm} / \mathrm{s}) / 2]$.

Figure 2: Placement of Dobhoff Tube Secured with a Nasal Bridle System
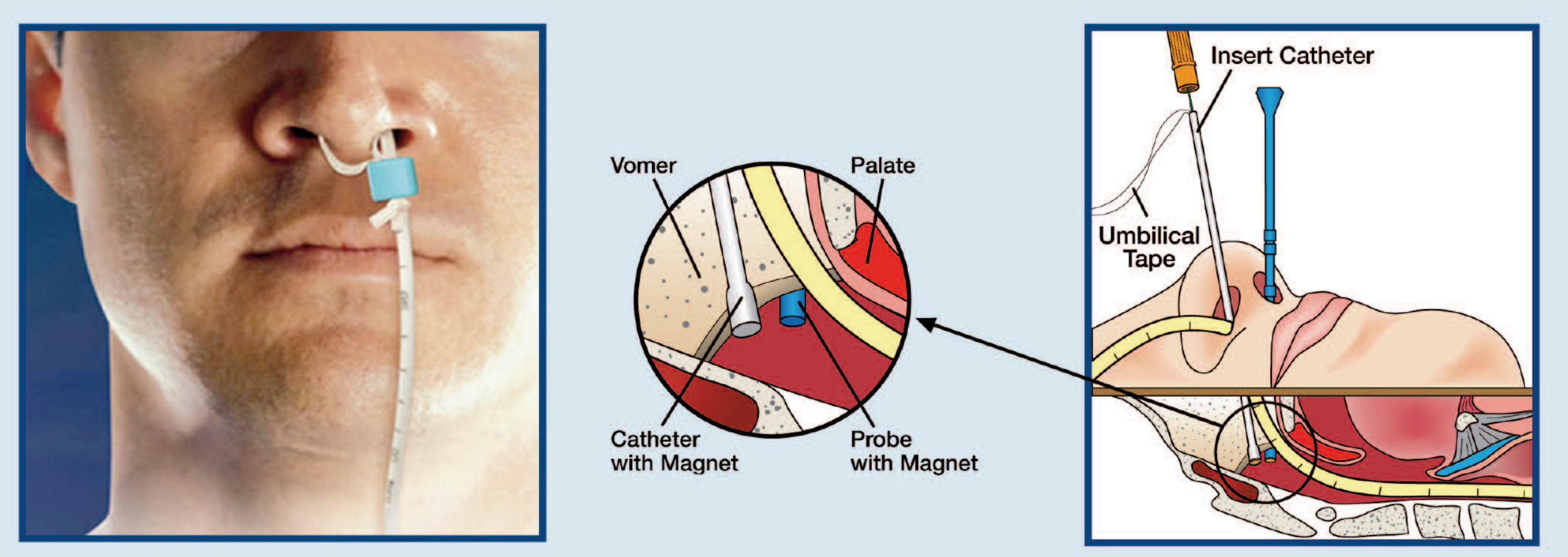

Image courtesy of Applied Medical Technology, Inc

\section{DISCUSSION}

As previously reported, there is an increased incidence of perioperative morbidity and mortality associated with a low psoas muscle area as measured on a CT scan of the abdomen and pelvis at the level of the L4 vertebra. This case demonstrates that home enteral nutrition supplementation with a DHT is an option to be considered for improving a patient's nutritiona status pre-liver transplant. Although complications such a vomiting, diarrhea and gastro-intestinal bleeding are possible with this intervention, it is overall low risk with regard to considered in for supplemental enteral feeding should be preserve their candidacy as a transplant candidate. Well-designed trials are needed to study this intervention to determine its overall effectiveness.

\section{REFERENCES}

Durand F, Buyse S, Francoz C, Laouénan C, Bruno O, Belghiti J, et al.Prognostic
value of muscle atrophy tomography. $J$ Hepatol. 2014. epud ahead of print.

2. Tandon P, Ney M, Irwin I, Ma MM, Gramlich L, Bain VG, et al. Severe muscle
depletion in patients on the liver transplant wait list: its prevalence and independent Krell RW, Kaul DR, Martin AR, Englesse MJ, Sonnenday CJ, Cai S, et al. Association between sarcopenia and the risk of serious infection
transplantation. Liver Transpl. 2013; 19 (12): $1396-402$

4. Merli $M$, Giusto $M$, Gentili F, Novelli $G$, Ferretti $G$, Riggio $O$, et al. Nutritional status:
its influence on the outcome of patients undergoing liver transplantation. Liver Int. its influence on the outcome of patients undergoing liver transplantation. Liver in.
2010;30(2):208-14.

5. Dimartini A, Cruz RJ Jr, Dew MA, Myaskovskk L, Goodpaster B, Fox K, et al. Muscle
mass predicts outcomes following liver transplatantation. Liver Transpl. mass predicts outco

6. Lang T, Streeper T, Cawthon P, Baldwin $\mathrm{K}$, Taaffe DR, Harris TB. Sarcopenia:
etiology, clinical consequences, intervention, and assessment. Osteoporos In 2010;21(4):543-59.

Fielding RA, Vellas B, Evans WJ, Bhasin S, Morley JE, Newman AB, et al. prevalence, etiology and consequences International working groensus definition: J Am Med Dir Assoc. 2011; 12(4):249-56.

8. Englesbe MJ, Patel SP, He K, Lynch RJ, Schaubel DE, Harbaugh C et al. Sarcopenia
and mortality after liver transplantation. J Am Coll Surg. 2010;2111(2):271-278. 